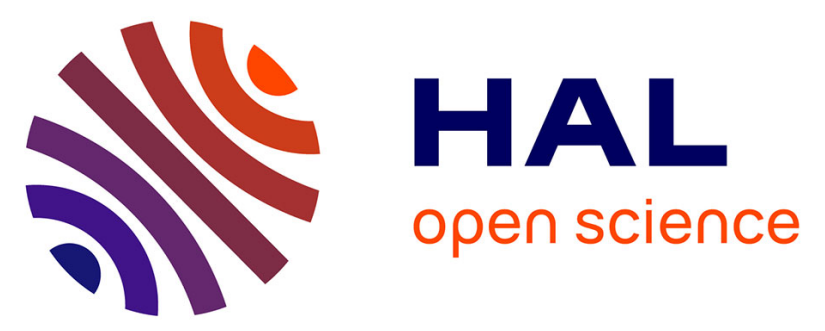

\title{
Use of the longitudinal mode of screen-printed piezoelectric cantilevers coated with PEUT for toluene detection. Comparison with silicon cantilevers
}

\author{
Hélène Debéda, Riadh Lakhmi, Claude Lucat, Isabelle Dufour
}

\section{- To cite this version:}

Hélène Debéda, Riadh Lakhmi, Claude Lucat, Isabelle Dufour. Use of the longitudinal mode of screenprinted piezoelectric cantilevers coated with PEUT for toluene detection. Comparison with silicon cantilevers. Sensors and Actuators B: Chemical, 2013, 187, pp.198-203. 10.1016/j.snb.2012.10.081 . hal-00743143

\author{
HAL Id: hal-00743143 \\ https://hal.science/hal-00743143
}

Submitted on 13 Nov 2014

HAL is a multi-disciplinary open access archive for the deposit and dissemination of scientific research documents, whether they are published or not. The documents may come from teaching and research institutions in France or abroad, or from public or private research centers.
L'archive ouverte pluridisciplinaire HAL, est destinée au dépôt et à la diffusion de documents scientifiques de niveau recherche, publiés ou non, émanant des établissements d'enseignement et de recherche français ou étrangers, des laboratoires publics ou privés. 


\section{Use of the longitudinal mode of screen-printed piezoelectric cantilevers coated with PEUT for toluene detection. Comparison with silicon cantilevers}

Hélène Debéda, Riadh Lakhmi, Claude Lucat, Isabelle Dufour Univ. Bordeaux, IMS, UMR 5218, 351 Cours de la Libération, 33405 Talence Cedex, France

\section{Corresponding author.}

Hélène Debéda

Université de Bordeaux, Laboratoire IMS, 351 Cours de la Libération, 33405 Talence Cedex, France Tel.: +33-5-4000-8336

Fax: +33-556 371545 .

E-mail address: helene.debeda@ims-bordeaux.fr. 


\begin{abstract}
:
Self-actuated and self-read-out piezoelectric cantilevers made of $\mathrm{Au} / \mathrm{PZT} / \mathrm{Au}\left(8 \times 2 \times 0.095 \mathrm{~mm}^{3}\right)$ beam layers on an alumina substrate are fabricated thanks to the association of screen-printing and sacrificial layer techniques. Then, PZT cantilevers used as piezoelectric resonant type sensors are functionalized with an organic PEUT layer $(\approx 30 \mu \mathrm{m})$ for toluene detection at room temperature. The first and second unusual in-plane 31-longitudinal modes presenting high resonant frequencies (respectively $70 \mathrm{kHz}$ and $214 \mathrm{kHz}$ ) and good quality factors $(\approx 200)$ are used for toluene detection. Sensitivities and LOD are compared for both modes. Due to their higher resonant frequency, PZT cantilevers using these longitudinal vibration modes have higher sensitivities $\left(15.0 \mathrm{mHz}_{\mathrm{ppm}}{ }^{-1}\right.$ at $70 \mathrm{kHz})$ than those actuated with the classical flexural mode of silicon cantilever $\left(0.9 \mathrm{mHz} . \mathrm{ppm}^{-1}\right.$ at $3 \mathrm{kHz}$ ). These interesting results demonstrate the potentialities of printed piezoelectric cantilevers for gas detection. Their performances are compared with those of silicon cantilevers actuated with transverse classical flexural modes.
\end{abstract}

Key words: PZT-cantilever, thick-layer, longitudinal vibration mode, toluene, PEUT, in-plane vibrations

\title{
1. Introduction
}

For a few decades, microcantilever-based chemical sensors have been widely investigated because of their high sensitivity at room temperature [1-4]. To perform detection of chemical species, in gas or liquid media, the microcantilever is usually coated with a chemically sensitive layer that aims to selectively sorb the target analyte. The sorbed species modifies the mechanical properties of the sensitive coating and therefore the mass, the rigidity and the surface stress of the microstructure. The sorbed species can consequently be detected either by measuring the microcantilever's resonant frequency shift (dynamic mode) or the microcantilever's quasi-static deflection (static mode). Polymers are often used as sensitive layers for gas detection (e.g. VOCs) because they allow reversible sorption. A wide range of polymers are employed for this purpose: PEUT, PDMS, PIB, PECH, PVA, PEI, PVP, PA, PMMA... [5,6]. More recently, silicon cantilevers have been functionalized with inorganic coatings like zeolite $[7,8]$. The major drawback of both polymer and zeolite layers is the partial selectivity to different species, and consequently the lack of sensor selectivity if only one cantilever with one sensitive layer is used. Usually, to address this issue, a multisensor approach using different sensitive layers with different partition coefficients for various species is used $[9,10]$. In this paper, we will not focus on the sensitive layer performance but on the advantage of an unusual mode of vibration for cantilever-based sensor in dynamic mode. Usually, the resonating cantilevers used for chemical sensing are vibrating in their first transverse flexural mode (out-of-plane vibrations, also called transverse bending mode), which is the resonant mode having the smallest resonant frequency. Due to the fact that the sensor sensitivity increases with the resonant frequency, alternative operational modes have already been used: higher transverse flexural modes $[11,12]$, lateral flexural modes [13-16] or torsional modes [17,18]. We propose here to use the axial mode, which is an inplane mode also called longitudinal or extensional mode $[19,20]$. To actuate and have an integrated read-out of this particular vibration mode, symmetric screen-printed piezoelectric cantilevers are designed, fabricated and tested. With the screen-printing thick film process, the thicknesses of the cantilevers are in the range of few tens of micrometers. The cantilever's width and length are in the millimeter range. Comparison to classical silicon cantilever having comparable dimensions used in transverse bending mode is done. For this purpose, toluene detection is performed with the same PEUT (PolyEtherUreThane) polymer sensitive coating in both cases.

In this paper, the fabrication of the screen-printed PZT cantilevers and their functionalization is first detailed. Electromechanical characterizations of the piezoelectric transducers, with and without sensitive coating, are then presented as well as correlations with analytical models. Finally, toluene detections are performed with the first and the second longitudinal modes. In this last part, a 
comparison between PZT and silicon microcantilevers allows focusing on advantages and drawbacks of the proposed microsensors.

\section{Fabrication and functionalization of screen-printed PZT cantilevers}

\subsection{PZT cantilever}

The self-actuated $8 \times 2 \times 0.095 \mathrm{~mm}^{3}$ piezoelectric cantilever is realized through screen-printing deposition associated to a sacrificial layer [21]. It is composed of a PZT $\left(\mathrm{Pb}\left(\mathrm{Zr}_{0,52} \mathrm{Ti}_{0,48}\right) \mathrm{O}_{3}\right)$ layer between two gold electrodes (Fig.1).The gold ink is commercially available (ESL8836 from ElectroScience Laboratories), whereas PZT and sacrificial layer inks are prepared at the IMS laboratory. The sacrificial layer ink is made of an epoxy- strontium carbonate $\left(\mathrm{SrCO}_{3}\right)$ mixture. The piezoelectric paste is prepared from a commercial piezoelectric PZT powder (PZ26 from Ferroperm) and $3 w t \% \mathrm{LBCu}\left(25 \mathrm{wt} \% \mathrm{Li}_{2} \mathrm{CO}_{3}, 40 \mathrm{wt} \% \mathrm{Bi}_{2} \mathrm{O}_{3}, 35 \% \mathrm{wt} \mathrm{CuO}\right)$ sintering aid blended with ESL400 organic vehicle (ElectroScience Laboratories) [22]. The different fabrication steps are given in figure 2. The anchor pad, based on PZT is first screen-printed on the alumina substrate and dried $20 \mathrm{~min}$ at $120^{\circ} \mathrm{C}$. Then, sacrificial layer is deposited on the substrate and polymerized $20 \mathrm{~min}$ at $120^{\circ} \mathrm{C}$. Finally, bottom electrode, PZT layer and top electrode are printed successively after drying at $120^{\circ} \mathrm{C}$ during $20 \mathrm{~min}$ between each deposition. To improve green sample's densification before firing, the dried layers are isostatically pressed $1 \mathrm{~min}$ at $1 \mathrm{kbar}$. The samples are then fired 2 hours at $900^{\circ} \mathrm{C}$ in air atmosphere. Finally, dissolution of sacrificial layer is performed in the 0.9 mole..$^{-1} \mathrm{H}_{3} \mathrm{PO}_{4}$ aqueous solution. Au/PZT/Au cantilevers shown on Fig. 3 are then poled with an electric field of $50 \mathrm{kVcm}^{-1}$, at a temperature of $280^{\circ} \mathrm{C}$, just below the PZT's Curie temperature.

\subsection{Functionalization}

For the deposition of a sensitive layer (polymer or inorganic) on a microcantilever, spray coating [23], drop coating [24] or spin coating [24] are classically used. The polymer PEUT (PolyEtherUreThane) is chosen because of its good partition coefficient to toluene $(K=1610)$ [26]. However, selectivity towards other BTEX compounds (benzene, ethylbenzene or xylene) and alcohols vapors is not achieved. Prior to its deposition by drop-coating on the top surface of the cantilevers, PEUT is dissolved in the dichloromethane solvent. A manual dispenser is used for this purpose. A thickness of approximately $30 \mu \mathrm{m}$ is measured with an optical profilometer (VeecoNT9080).

\section{Electro-mechanical characterization of screen-printed PZT cantilevers}

\subsection{Measurements}

Electrical measurements of poled samples are carried out with an impedancemeter (HP 4194A). An example of the conductance curve obtained on the $8 \times 2 \times 0.095 \mathrm{~mm}^{3}$ uncoated cantilever confirms the piezoelectric behavior of the PZT cantilevers (Fig. 4). The resonance peaks are attributed to the inplane 31-longitudinal vibration modes (31 refers to the piezoelectric effect: the electrical polarization is perpendicular to the mechanical displacement).

Without coating, the three first resonant frequencies values are respectively 70,214 and $362 \mathrm{kHz}$. The quality factor Q 200 of the first peak, slightly decreases for the second and third modes. Mechanical analysis performed with an optical vibrometer allowing both out-of-plane (Doppler interferometry) and in-plane (stroboscopy) vibration measurements (Polytec MSA 500) confirm that the resonant modes seen on the impedance measurements are in-plane longitudinal resonant modes. Moreover, the optical measurement enables to estimate the deflection of the out-of-plane transverse bending modes (first and second modes) which are not visible on the impedance measurement. Few hundreds of picometers are measured with the optical vibrometer (Fig.5). The small bending deflection value is due to the fact that the microcantilever is designed with a symmetrical geometry in order to minimize the bending-modes deflection. Thanks to the design, the minimization of the unwanted bending modes' amplitude is confirmed by the electrical signature where these modes are not detected, while detecting the desired in-plane 31-longitudinal modes (Fig.4). Thus, in future work this symmetrical microcantilever design will facilitate operation of the microresonator in closed-loop operation, where the microcantilever is the frequency-determining element in an amplifying feedback loop. Besides, 
high resonant frequencies and good quality factors justify their choice for gas sensing. These modes, easily recordable by impedance analysis, show the PZT cantilever's ability for actuation/sensing with low power consumption.

After deposition of the PEUT sensitive layer, electrical measurement shows a decrease of both resonant frequency and quality factor (Fig.6) (Tab.1).

\subsection{Correlations with analytical models}

For the multilayer piezoelectric cantilever structure, the analytical expression of the 31-longitudinal modes' resonant frequency can be expressed by [27]:

where

$$
f_{31}^{(n)}=\frac{\lambda_{31}^{(n)}}{2 \pi L} \sqrt{\frac{h_{P Z T} E_{P Z T}+2 h_{A u} E_{A u}}{h_{P Z T} \rho_{P Z T}+2 h_{A u} \rho_{A u}}}
$$

$$
\lambda_{31}^{(n)}=\frac{(2 n-1) \pi}{2}
$$

with $n, L, h, E$ and $\rho$ the mode's order, the length, the thickness, the Young's modulus and the mass density respectively. The indexes $P Z T$ and $A u$ refer to the piezoelectric layer and the gold electrodes, respectively.

To take into account of the sensitive layer the equation (1) of the resonant frequency has to be modified:

$$
f_{31}^{(n)}=\frac{\lambda_{31}^{(n)}}{2 \pi L} \sqrt{\frac{h_{P Z T} E_{P Z T}+2 h_{A u} E_{A u}+h_{P E U T} E_{P E U T}^{\prime}}{h_{P Z T} \rho_{P Z T}+2 h_{A u} \rho_{A u}+h_{P E U T} \rho_{P E U T}}}
$$

where the index PEUT is for the sensitive layer and the exponent 'on the Young's modulus is for the real part when it is a complex value due to viscoleasticity.

Due to its viscoelastic properties, the PEUT layer's Young's modulus depends on the frequency. For the considered resonant frequencies (less than $500 \mathrm{kHz}$ ), polymers such as PIB, PEUT,.. have Young's modulus lower than $0.5 \mathrm{GPa}$. According to estimated Young's moduli ( $E_{P Z T}=36.5 \mathrm{GPa}$ and $\left.E_{A u}=55 \mathrm{GPa}\right)$ and thicknesses $\left(h_{P Z T}=80 \mu \mathrm{m}\right.$ and $\left.h_{A u}=7.5 \mu \mathrm{m}\right)$ of screen-printed PZT and gold layers, the modification of the rigidity (numerator in Eq.3) due to the PEUT coating is negligible. The decrease of the resonant frequency can then be fully attributed to the cantilever's mass increase (denominator of Eq.3). Then, using the mass density of the different materials $\left(\rho_{A U T}=18500 \mathrm{~kg} / \mathrm{m}^{3,} \rho_{P Z T}=6000 \mathrm{~kg} / \mathrm{m}^{3}\right.$, $\rho_{P E U T}=1040 \mathrm{~kg} / \mathrm{m}^{3}$ ), the sensitive layer's thickness can be estimated at $21 \mu \mathrm{m}$ using Eq.3. The fact that the value differs from the measured PEUT thickness with the optical profilometer $(30 \mu \mathrm{m})$ is attributed to the incertitude on the estimated values for both the Young's moduli and thicknesses of the gold and PZT layers.

The quality factor is not very high in air even before the polymer deposition because of the internal losses in the piezoelectric layer. The cantilever's mass increase with the PEUT layer deposition is supposed to increase the quality factor if no additional losses are added. Then, the decrease of the quality factor is due to losses in the layer which are viscoelastic losses as in the case of transverse bending vibration [28]. Using the numerical values of Tab.1, the quality factor $Q_{P E U T}$, due to the viscoelastic losses in the layer, is estimated to 610. In this multilayer configuration and for the longitudinal modes, the quality factor associated to viscoelastic losses in the PEUT layer can be expressed as follow:

$$
Q_{P E U T}=\frac{h_{P Z T} E_{P Z T}+2 h_{A u} E_{A U}+h_{P E U T} E_{P E U T}^{\prime}}{h_{P E U T} E^{\prime}{ }_{P E U T}}
$$

where the exponent " is related the Young's modulus's imaginary part.

As in the case of the resonant frequency, the term due to the elastic part of the PEUT Young's modulus is negligible compared to the other ones (numerator of Eq.4). Then, using numerical values at $f_{r, 31}=70 \mathrm{kHz}$ (Tab. 1), it is possible to estimate the imaginary part of PEUT's Young's modulus E" ${ }_{P E U T}$ $\sim 0.3 \mathrm{GPa}$, whose value is close to that of PIB [29]. 


\section{Toluene detection}

\subsection{Experiments}

- Screen-printed PZT cantilevers coated with PEUT

The functionalized PZT cantilevers are placed in a gas chamber $\left(500 \mathrm{~mm}^{3}\right)$ under a controlled gas flow $(100 \mathrm{ml} / \mathrm{min})$ of nitrogen. Different concentrations of toluene are introduced into the chamber using a vapor generator. During the experiments, the impedance of the functionalized cantilevers is monitored using the HP4194A impedancemeter. The whole system is controlled under a LabVIEW environment. During the tests, first and second 31-longitudinal modes are measured. Influence of oscillating voltage and bias voltage is first studied to have the best sensitivity and lowest noise. For a $0.5 \mathrm{~V}$ oscillating voltage, a bias voltage of $40 \mathrm{~V}$ doesn't lead to better sensitivities than without bias. It indicates that the polarization of the piezoelectric material is already maximized and stable. On the other hand, without bias, oscillating voltage allowing actuation of the cantilever has an influence on the detection performance of the cantilevers, more precisely on the measurement noise. By varying the oscillating voltage from $0.3 \mathrm{~V}$ to $1 \mathrm{~V}$, the sensitivity to toluene remains the same whereas the signal noise changes. Indeed, the amplitude's noise decreases with the oscillating voltage amplitude, of more than a factor 10 for a change between $1 \mathrm{~V}$ and $0.5 \mathrm{~V}$ or $0.5 \mathrm{~V}$ and $0.3 \mathrm{~V}$. This is of importance in order to reduce the Limit Of Detection LOD $=3 \Delta f_{\text {noise }} / S_{C A}$ which is proportional to the noise. Note that with a lower tested oscillating voltage (amplitude 0.1V), no actuation of the PZT cantilever is observed with the impedance measurement.

For the comparison of first and second longitudinal modes, a $0.3 \mathrm{~V}$ oscillating voltage is thus chosen. The resonant frequency evolution under different toluene concentrations (from 260ppm to 1050ppm) is shown in Fig. 7. Using a single 260ppm concentration, a good reproducibility of the PZT cantilever's response is observed (Fig. 8). The relative resonant frequency shifts under the different toluene concentrations $\left(C_{A}\right)$ are given in Fig. 9. The measured sensitivities $S_{C A}=\frac{d f_{31}}{d C_{C}}$ are respectively $0.015 \mathrm{~Hz} . \mathrm{ppm}^{-1}$ and $0.048 \mathrm{~Hz} . \mathrm{ppm}^{-1}$ for the first and second longitudinal modes $C^{-1} C_{\text {hderning }}$ the relative sensitivities values of $0.21510^{-6} \mathrm{ppm}^{-1}$ and $0.22210^{-6} \mathrm{ppm}^{-1}$ are obtained, respectively for the first and second modes.

\section{- Silicon PEUT-coated cantilevers}

Microfabricated silicon cantilevers of uniform rectangular section, coated with sprayed-PEUT, have been also used in previous works for toluene detection (Fig. 10). The process developed by ESIEE (http:/www.esiee.fr), calls upon 5 levels of masks [23]. The three first steps ensure the development of the strain gauge and the electrical contact. The two last steps define the geometry of the millimeter sized microcantilever. The actuation is electromagnetic and allows the out-of-plane transverse bending resonance mode. The performances of the silicon cantilevers also tested at IMS laboratory are compared to those of PZT cantilevers (Tab. 2). For this purpose, because of PEUT deposit of different thicknesses, a normalized relative sensitivity is defined $\left(S_{C A} / f_{\text {res }} / h_{\text {PEUT }}\right)$.

\subsection{Discussion}

As expected, sensitivity to gas $S_{C A}$ is higher for the second longitudinal mode whereas the relative sensitivities $\left(S_{C A} / f_{31}\right)$ are equivalent for both longitudinal modes in accordance to equation (5)

$$
S_{C_{A}}=\left|\frac{d f_{31}^{(n)}}{d C_{A}}\right|=\frac{f_{31}^{(n)}}{2} \frac{K h_{P E U T}}{\rho_{P Z T} h_{P Z T}+2 \rho_{A U} h_{A U}+\rho_{P E U T} h_{P E U T}}
$$

where $C_{A}$ and $K$ are respectively the gas concentration and partition coefficient of the PEUT with respect to the analyte (Fig. 9).

A signal noise of $5.0 \mathrm{~Hz}$ for the second longitudinal mode is nevertheless higher than those of the first longitudinal mode of $0.4 \mathrm{~Hz}$. Consequently, the first longitudinal mode appears to be more interesting for detection at low gas concentrations. For the first longitudinal mode, calculations of theoretical sensitivities are made for $L=8 \mathrm{~mm}, h_{P Z T}=80 \mu \mathrm{m}, h_{A U}=7.5 \mu \mathrm{m}, h_{P E U T}=30 \mu \mathrm{m}, \rho_{P Z T}=6000 \mathrm{~kg} / \mathrm{m}^{3}$, 
$\rho_{A U}=18500 \mathrm{~kg} / \mathrm{m}^{3}, \rho_{P E U T}=1040 \mathrm{~kg} / \mathrm{m}^{3}$. Discrepancy observed between theoretical and experimental sensitivities $\left(S_{C A \text { exp }} / S_{C A t h e o r}=1.8\right)$ may be attributed to inhomogeneous PEUT layers. In this case, the Limit of Detection ( $\mathrm{LOD}=3 \Delta f_{\text {noise }} / S_{C A}$ ) is estimated to $80 \mathrm{ppm}$.

Sensitivities of low cost screen-printed PZT cantilevers under toluene are close to those of silicon functionalized cantilevers. Nevertheless, the quality factor of the silicon cantilever is still higher and the LOD of silicon cantilever is lower assuming the lower noise value.

\section{Conclusion}

Low cost screen-printed PZT cantilevers allow generation of unusual in-plane 31-longitudinal modes working at higher frequencies $(\sim 70 \mathrm{kHz}$ for the first 31 mode) than out-of-plane transverse bending modes generally used in silicon cantilevers with electromagnetic actuation [23] or piezoelectric actuation [30]. Coated with a $30 \mu \mathrm{m}$ PEUT sensitive layer, self-excited piezoelectric PZT cantilevers with integrated read-out present sensitivities to toluene of $0.015 \mathrm{~Hz} . \mathrm{ppm}^{-1}$ for the first longitudinal mode, and $0.048 \mathrm{~Hz} . \mathrm{ppm}^{-1}$ for the second mode. Due to lower noise giving a LOD of $80 \mathrm{ppm}$, the first mode is preferred to the second one. Compared to silicon cantilevers coated with PEUT and having also millimeter sizes, limitations of screen-printed piezoelectric cantilevers are nevertheless due to lower quality factor in gas medium and higher noise. Physico-chemical properties are currently studied to improve the PZT compacity which could be a way to increase the quality factor and decrease the noise value. Moreover, a combination of self-excited piezoelectric cantilevers coated with a more sensitive layer should also give a more sensitive gas sensors. Indeed, self-excited piezoelectric cantilevers functionalized with zeolite for freon detection exhibit a sensitivity of $0.24 \mathrm{~Hz}$. $\mathrm{ppm}^{-1}$ [30]. As well, active carbon used as sensitive layer on screen-printed PZT cantilevers lead to a sensitivity of $13 \mathrm{~Hz} . \mathrm{ppm}^{-1}$ under benzene [31]. Use of self-actuated PZT cantilevers for species detection in liquid media could also be promising, even if the quality factor in air is smaller than those of the transverse bending mode of silicon-based microcantilevers. With these self-actuated piezoelectric cantilevers vibrating in longitudinal modes, very good quality factors are actually obtained in liquid even for high viscosity fluids, because viscous losses are small with this in-plane mode [32].

\section{References}

[1] K.M. Goeders, J.S. Colton and L. A. Bottomley, "Microcantilevers: Sensing Chemical Interactions via Mechanical Motion", Chemical Reviews, 108, 522-542 (2008).

[2] A. Boisen, S. Dohn, S.S. Keller, S. Schmid and M. Tenje, "Cantilever-like micromechanical sensors", Reports on Progress in Physics, 74, 1-31 (2011).

[3] X. Li and D.W. Lee, "Integrated microcantilevers for high-resolution sensing and probing", Measurement Science and Technology, 23, 022001, 40pp, (2012).

[4] M. Sepaniak, P. Datskos, N. Lavrik and C. Tipple, "Microcantilever Transducers: A new Approach in Sensor Technology", Analytical Chemistry, 74, 568-575 (2002).

[5] D. Lange, C. Hagleitner, A. Hierlemann, O. Brand and H. Baltes, "Complementary metal oxide semiconductor cantilever arrays on a single chip: mass-sensitive detection of volatile organic compounds", Analytical Chemistry, 74, 3084-3095 (2002).

[6] Y. Donga, W. Gaoa, Q. Zhouc, Y. Zhenga and Z. Youa, "Characterization of the gas sensors based on polymer-coated resonant microcantilevers for the detection of volatile organic compounds", Analytica Chimica Acta, 671, 85-91 (2010)

[7] M. A. Urbitzondo, I. Pellejero, M. Villarroya, J. Sese, M.P. Pina, I. Dufour and J. Santamaria, "Zeolite-modified cantilevers for the sensing of nitrotoluene vapors", Sensors and Actuators B, 137, pp. 608-616 (2009).

[8] M. A. Urbitzondo, A. Peralta, I. Pellejero, J. Sese, M.P. Pina, I. Dufour and J. Santamaria, "Detection of organic vapours with Si cantilevers coated with inorganic (zeolites) or organic (polymer) layers", Sensors and Actuators B, in press (2012).

[9] H.P. Lang, M. Hegner and C. Gerber, "Cantilever array sensors", Materials Today, 8, 30-36 (2005). 
[10] R. Archibald, P. Datskos, G. Devault, V. Lamberti, N. Lavrik, D. Noid, M. Sepaniak and P. Dutta, "Independent component analysis of nanomechanical responses of cantilever arrays", Analytica Chimica Acta, 584, 101-105 (2007).

[11] F. Lochon, I. Dufour and D. Rebière, "An alternative solution to improve sensitivity of resonant microcantilever chemical sensors: comparison between using high-order modes and reducing dimensions", Sensors and Actuators B, 108, 979-985 (2005).

[12] D. Maraldo and R. Mutharasan, "Mass-change sensitivity of high-order mode of piezoelectricexcited millimeter-sized cantilever (PEMC) sensors: Theory and experiments", Sensors and Actuators B, 143, 731-739 (2010).

[13] L.A. Beardslee, K.S. Demirci, Y. Luzinova, B. Mizaikoff, S.M. Heinrich, F. Josse and O. Brand, "Liquid-Phase Chemical Sensing Using Lateral Mode Resonant Cantilevers", Analytical Chemistry, 82, 7542-7549 (2010).

[14] L.A. Beardslee, F. Josse, S.M. Heinrich, I. Dufour and O. Brand, "Geometrical considerations for the design of liquid-phase biochemical sensors using a cantilever's fundamental in-plane mode", Sensors and Actuators B, 164, 7-14 (2012).

[15] M. Gil, T. Manzaneque, J. Hernando-Garcıa, A. Ababneh, H. Seidel and J. L. Sanchez-Rojas, "Selective modal excitation in coupled piezoelectric microcantilevers", Microsystem Technology, 18, 917-924 (2012)

[16] V. Ruiz, J. Hernando-Garcia, A. Ababneh, H. Seidel, U. Schmid, J. L. Sanchez-Rojas, Modelling and characterization of AIN-actuated microcantilevers vibrating in the first in-plane mode, Microsyst Technol (2012) 18:997-1001

[17] C. P. Green and J. E. Sader, "Torsional frequency response of cantilever beams immersed in viscous fluids with applications to the atomic force microscope", Journal of Applied Physics, 92, 6262, (2002).

[18] T. Cai, F. Josse, S.M. Heinrich, O. Brand, N. Nigro and I. Dufour, "Resonant Characteristics of Rectangular Microcantilevers Vibrating Torsionally in Viscous Liquid Media", IEEE International Frequency Control Symposium, Baltimore, Maryland, USA, 21-24 May 2012

[19] J. L. Fu and F. Ayazi, "Dual-Mode Piezo-on-Silicon Resonant Temperature and Humidity Sensor for Portable Air Quality Monitoring Systems," in IEEE Sensors Conference, Waikoloa, Big Island, Hawaii, 2010, pp. 2131-2135.

[20] V. Ruiz, T. Manzaneque, J. Hernando-García, A, Ababneh, H. Seidel, E. Vikhagen and J.L. Sánchez-Rojas, "Optical and electrical characterization of in-plane modes of AIN-based piezoelectric vibrating MEMS", $23^{\text {rd }}$ Micromechanics and Microsystems Europe Workshop, September 9 - 12, 2012, Ilmenau, Germany.

[21] C. Lucat, P. Ginet, C. Castille, H. Debéda and F. Ménil, "Microsystems elements based on freestanding thick-films made with a new sacrificial layer process", Microelectronics Reliability, 48, 872 875 (2008).

[22] R. Lakhmi, H. Debéda, M. Maglione, I. Dufour and C. Lucat,' "Study of screen-printed PZT cantilevers both self-actuated and self-read-out", International Journal on Applied Ceramics, accepted for publication, December 2012

[23] L. Fadel, F. Lochon, I. Dufour and O. Français, "Chemical sensing: millimeter size resonant microcantilever performance", Journal of Micromechanics and Microengineering, 14, S23-S30, (2004).

[24] J. Amirola, Angel Rodríguez, Luis Castañer, J.P. Santos, J. Gutiérrez and M.C. Horrillo, "Micromachined silicon microcantilevers for gas sensing applications with capacitive read-out", Sensors and actuators B, 111-112, 246-253 (2005).

[25] T.A. Betts, C. A. Tipple and M. J. Sepaniak, "Selectivity of chemical sensors based on microcantilevers coated with thin polymer films", Analytical Chimica Acta, 422, 89-99 (2000).

[26] P. Kurzawski, C. Hagleitner and A. Hierlemann, "Detection and discrimination capabilities of a multitransducer single-chip gas sensor system", Analytical Chemistry, 78, 6910-6920 (2006).

[27] R. D. Blevins, Formulas for Natural Frequency and Mode Shape, Van Nostrand Reinhold, New York (1979). 
[28] I. Dufour, F. Lochon, S. Heinrich, F. Josse and D. Rebière, "Effect of coating viscoelasticity on quality factor and limit of detection of microcantilever chemical sensors", IEEE Sensors Journal, 7, 230-236 (2007).

[29] J. D. Ferry, Viscoelastic Properties of Polymers. New York: Wiley (1961).

[30] J. Zhou, P. Li, S. Zhang, Y. Huang, P. Yang, M. Bao and G. Ruan, "Self excited piezoelectric microcantilever for gas detection", Microelectronic Engineering, 69, 37-46, (2003).

[31] R. Vázquez, R. Lakhmi, H. Debéda, F. J. Arregui, C. R. Zamarreño, M.Delgado, C. Lucat and E. Llobet, "Functionalized screen-printed PZT cantilevers for room temperature benzene detection", Procedia Engineering, 25, 1077-1080 (2011).

[32] C. Castille, I. Dufour, and C. Lucat, "Longitudinal vibration mode of piezoelectric thick-film cantilever-based sensors in liquid media ", Applied Physics Letters 96 -154102 (2010) 


\section{Tables}

\begin{tabular}{|c|c|c|c|}
\hline \multicolumn{2}{|c|}{ Before PEUT deposition } & \multicolumn{2}{c|}{ After PEUT deposition } \\
\hline $\begin{array}{c}\text { Resonant } \\
\text { frequency }(\mathrm{kHz})\end{array}$ & Quality factor & $\begin{array}{c}\text { Resonant } \\
\text { frequency }(\mathrm{kHz})\end{array}$ & Quality factor \\
\hline 70.605 & 185 & 69.609 & 142 \\
\hline
\end{tabular}

Tab.1: Resonant frequency and quality factor of the first in-plane longitudinal mode before and after PEUT deposition

\begin{tabular}{|c|c|c|c|c|c|c|c|}
\hline Cantilever type & $f_{\text {res }} /$ mode & $Q$ & $\begin{array}{c}S_{C A} \\
\left(10^{-4} \mathrm{~Hz}_{\mathrm{ppm}} \mathrm{ppm}^{-1}\right)\end{array}$ & $\begin{array}{c}S_{C A} / f_{\text {res }} \\
\left(10^{-6} \mathrm{ppm}^{-1}\right)\end{array}$ & $\begin{array}{c}\text { Normalized } \\
\text { sensitivity } \\
S_{C A} / f_{\text {res }} / h_{P E U T} \\
\left(10^{-6} \mathrm{ppm}^{-1} \cdot \mathrm{mm}^{-1}\right)\end{array}$ & $\begin{array}{c}\text { Noise } \\
(\mathrm{mHz})\end{array}$ & $\begin{array}{c}\text { LOD } \\
(\mathrm{ppm})\end{array}$ \\
\hline $\begin{array}{c}\mathrm{PZT}, \text { cantilever } \\
8 \times 2 \times 0.095 \mathrm{~mm}^{3} \\
30 \mu \mathrm{m} \text { PEUT }\end{array}$ & $\begin{array}{c}70 \mathrm{kHz} \\
\text { /in-plane } \\
\text { longitudinal }\end{array}$ & 142 & 150 & 0.22 & 7.3 & 400 & 80 \\
\hline $\begin{array}{c}\text { Si } 5 \times 0.4 \times 0.059 \mathrm{~mm}^{3} \\
18 \mu \mathrm{m} \text { PEUT }\end{array}$ & $\begin{array}{c}3 \mathrm{kHz} \\
\text { /out-of- } \\
\text { plane } \\
\text { flexural }\end{array}$ & 940 & 8.9 & 0.30 & 16.7 & 14 & 47 \\
\hline
\end{tabular}

Tab. 2: Comparison of the performance between screen-printed PZT and silicon cantilever 


\section{Figure Captions}

Fig.1. Scheme of the Au/PZT/Au screen-printed cantilever

Fig.2. Fabrication steps of the PZT cantilever (a) screen-printing of the PZT pad (b) screen-printing of the sacrificial layer (c) screen-printing of the bottom gold electrode (d) screen-printing of the PZT cantilever (e) screen-printing of the top gold electrode (f) sacrificial layer elimination with $\mathrm{H}_{3} \mathrm{PO}_{4}$ solution after co-firing $(\mathrm{g})$ poling of the PZT cantilever (cross-view)

Fig.3. Photograph of the $8 \times 2 \times 0.095 \mathrm{~mm}^{3}$ piezoelectric cantilever

Fig.4. Conductance measurements revealing the three in-plane 31 longitudinal modes for the $2 \times 8 \times 0.095 \mathrm{~mm}^{3} \mathrm{PZT}$ cantilever (oscillating voltage $0.5 \mathrm{~V}$ )

Fig.5. Mechanical spectrum observed for the $2^{\text {nd }}$ bending mode of the $2 \times 8 \times 0.095 \mathrm{~mm}^{3} P Z T$ cantilever (oscillating voltage $0.25 \mathrm{mV}$ )

Fig.6. Spectrum of the conductance for the first longitudinal mode before and after deposition of a PEUT layer (0.3V oscillating voltage)

Fig.7. Resonant frequency evolution under different toluene concentrations measured for the first and second longitudinal 31 modes of the $8 \times 2 \times 0.095 \mathrm{~mm}^{3}$ PZT cantilever ( $0.3 \mathrm{~V}$ oscillating voltage)

Fig.8. Repeatability of the cantilever's response for a toluene concentration of $260 \mathrm{ppm}(0.3 \mathrm{~V}$ oscillating voltage)

Fig.9. Relative resonant frequency shifts as a function of toluene concentrations measured for the first and second longitudinal 31 modes of the $8 \times 2 \times 0.095 \mathrm{~mm}^{3} \mathrm{PZT}$ cantilever ( $0.3 \mathrm{~V}$ oscillating voltage)

Fig.10. Silicon cantilever $\left(5 \times 0.4 \times 0.059 \mathrm{~mm}^{3}\right)$ with electromagnetic actuation and piezoresistive measurement (a) photograph (b) electrical connection diagram 


\section{List of Figures}

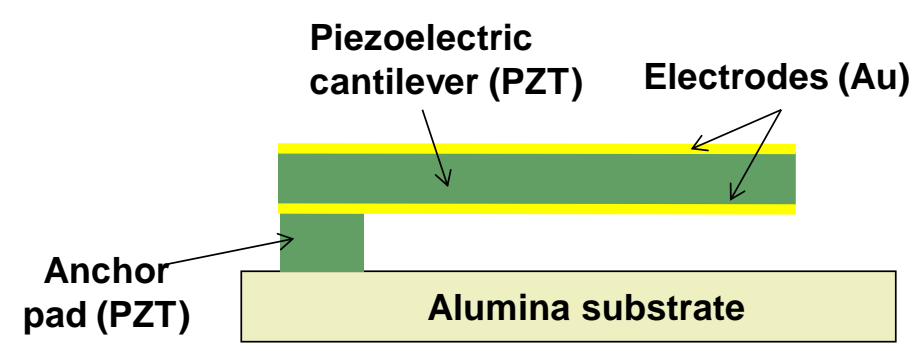

Fig.1: Scheme of the Au/PZT/Au screen-printed cantilever

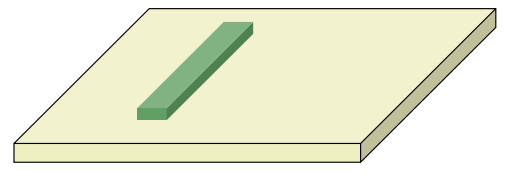

a)
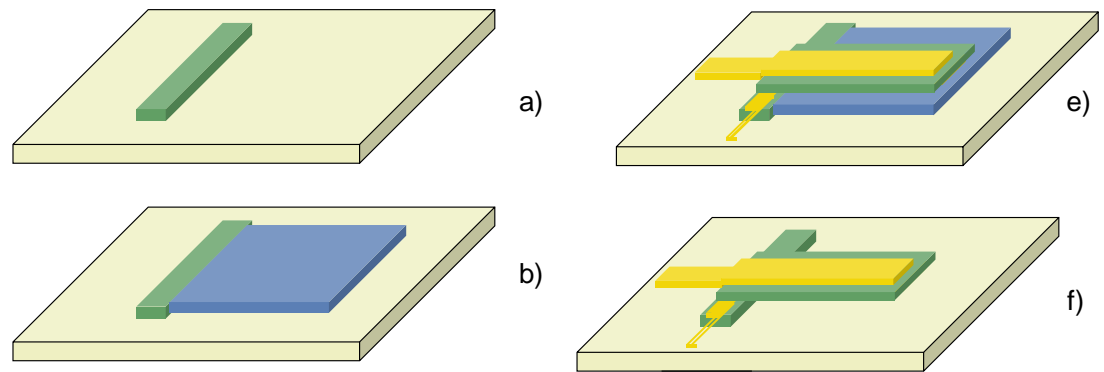

b)
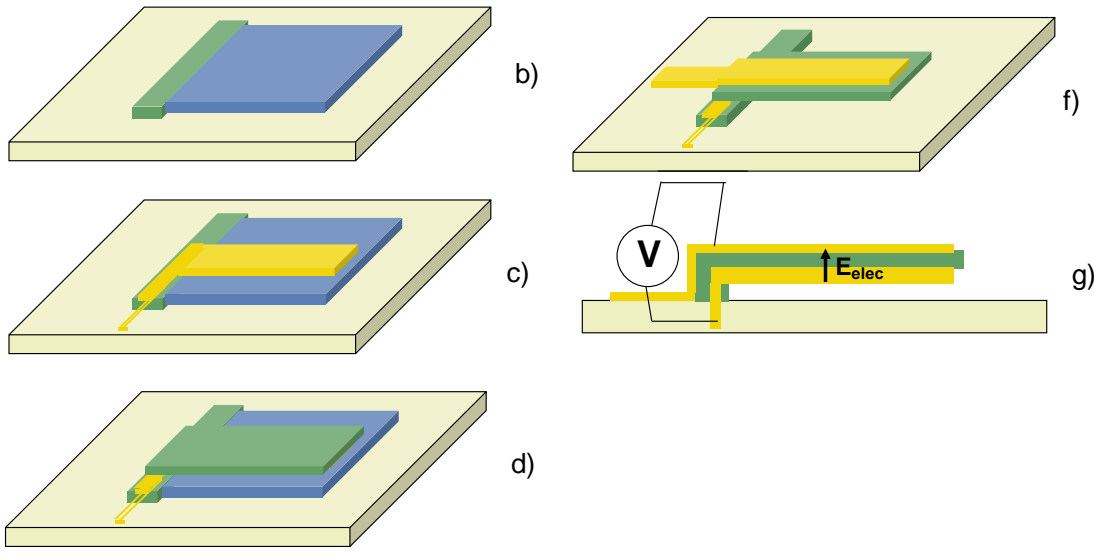

d)

Fig.2. Fabrication steps of the PZT cantilever (a) screen-printing of the PZT pad (b) screen-printing of the sacrificial layer (c) screen-printing of the bottom gold electrode (d) screen-printing of the PZT cantilever (e) screen-printing of the top gold electrode (f) sacrificial layer elimination with $\mathrm{H}_{3} \mathrm{PO}_{4}$; after co-firing $(\mathrm{g})$ poling of the PZT cantilever (cross- view) 


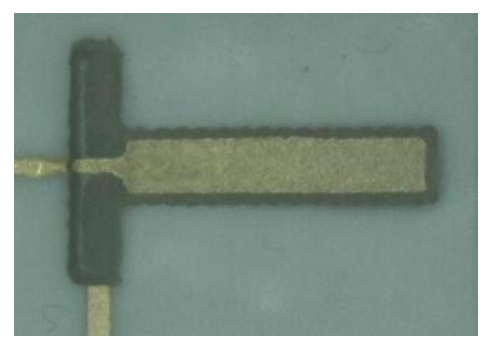

Fig.3. Photograph of the $8 \times 2 \times 0.095 \mathrm{~mm}^{3}$ piezoelectric cantilever

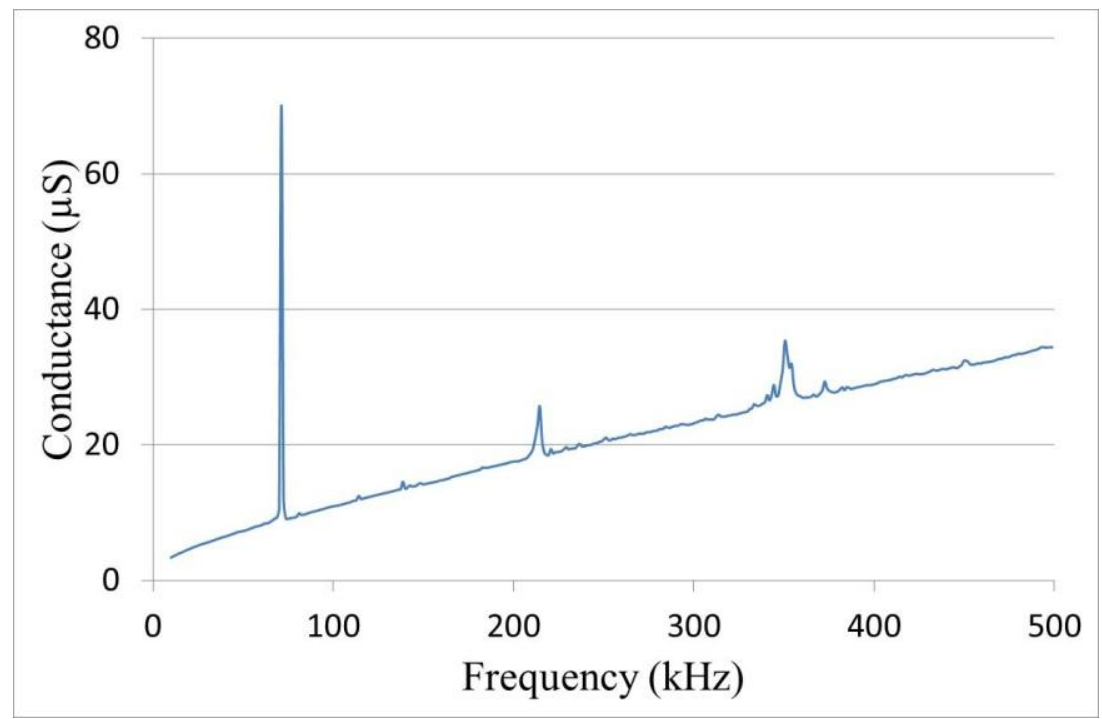

Fig.4: Conductance measurements revealing the three in-plane 31 longitudinal modes for the $2 \times 8 \times 0.095 \mathrm{~mm}^{3}$ PZT cantilever (oscillating voltage $0.5 \mathrm{~V}$ )

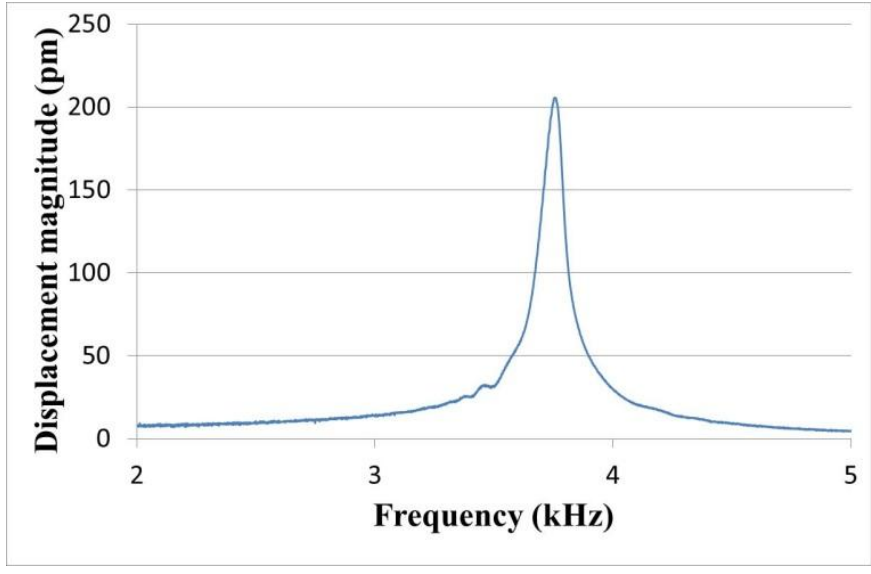

Fig.5: Mechanical spectrum observed for the $2^{\text {nd }}$ bending mode of the $2 \times 8 \times 0.095 \mathrm{~mm}^{3} P Z T$ cantilever (oscillating voltage $0.25 \mathrm{mV}$ ) 


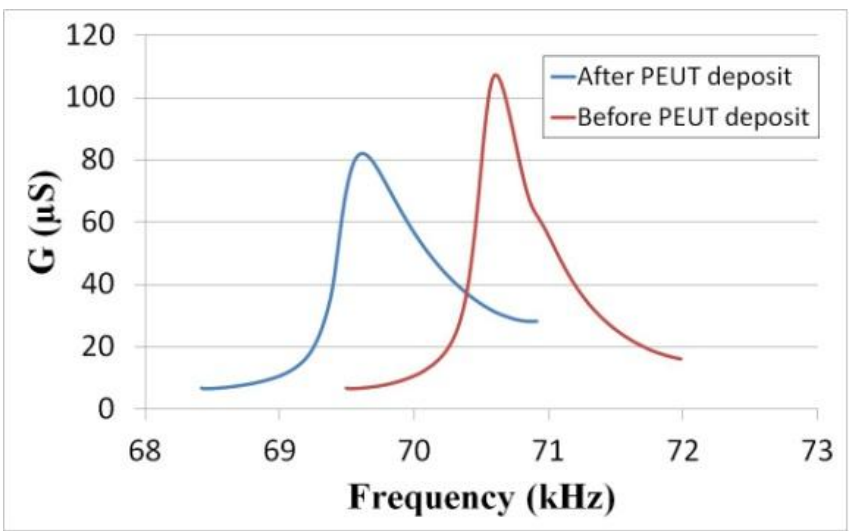

Fig.6. Spectrum of the conductance for the first longitudinal mode before and after deposition of a PEUT layer (0.3V oscillating voltage).

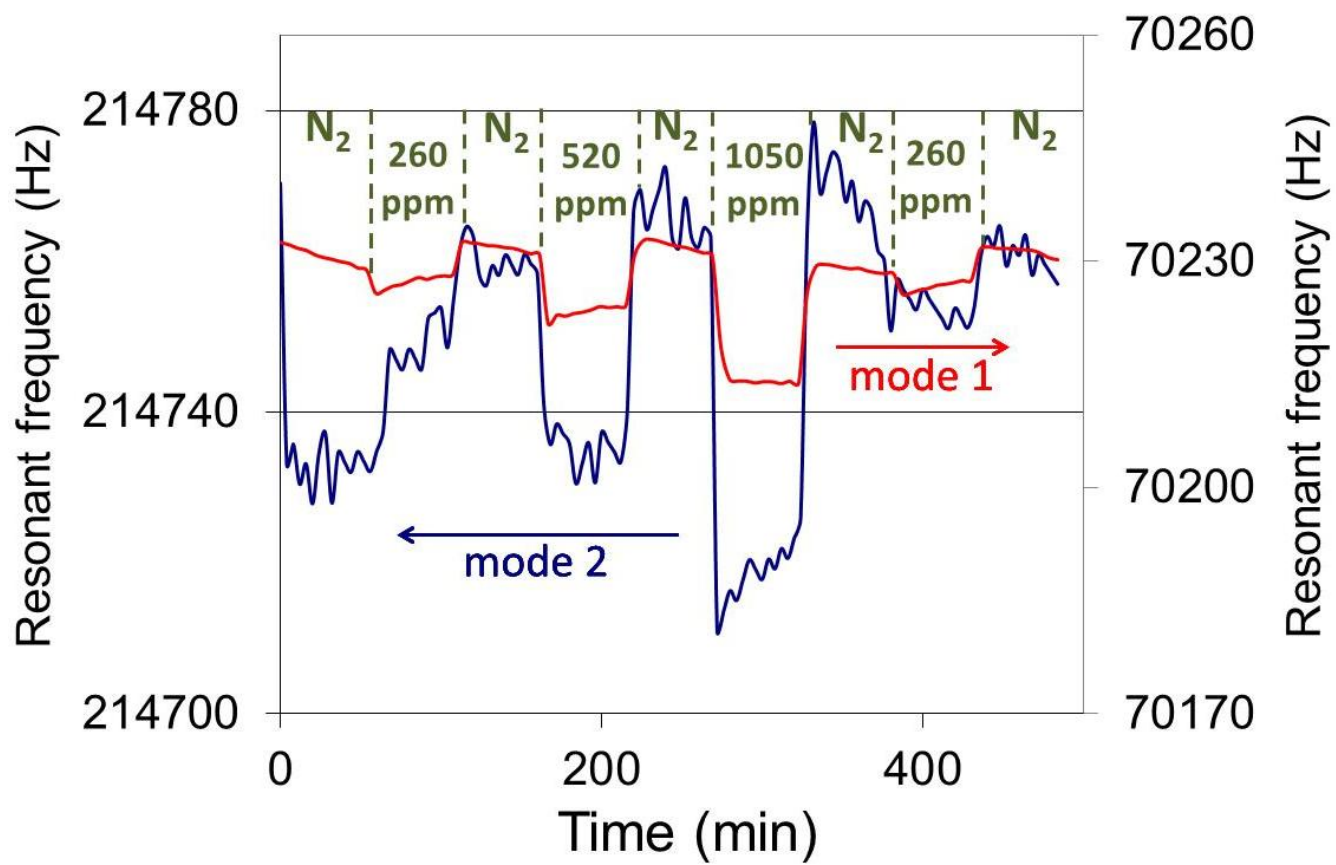

Fig.7. Resonant frequency evolution under different toluene concentrations measured for the first and second longitudinal 31 modes of the $8 \times 2 \times 0.095 \mathrm{~mm}^{3}$ PZT cantilever ( $0.3 \mathrm{~V}$ oscillating voltage) 


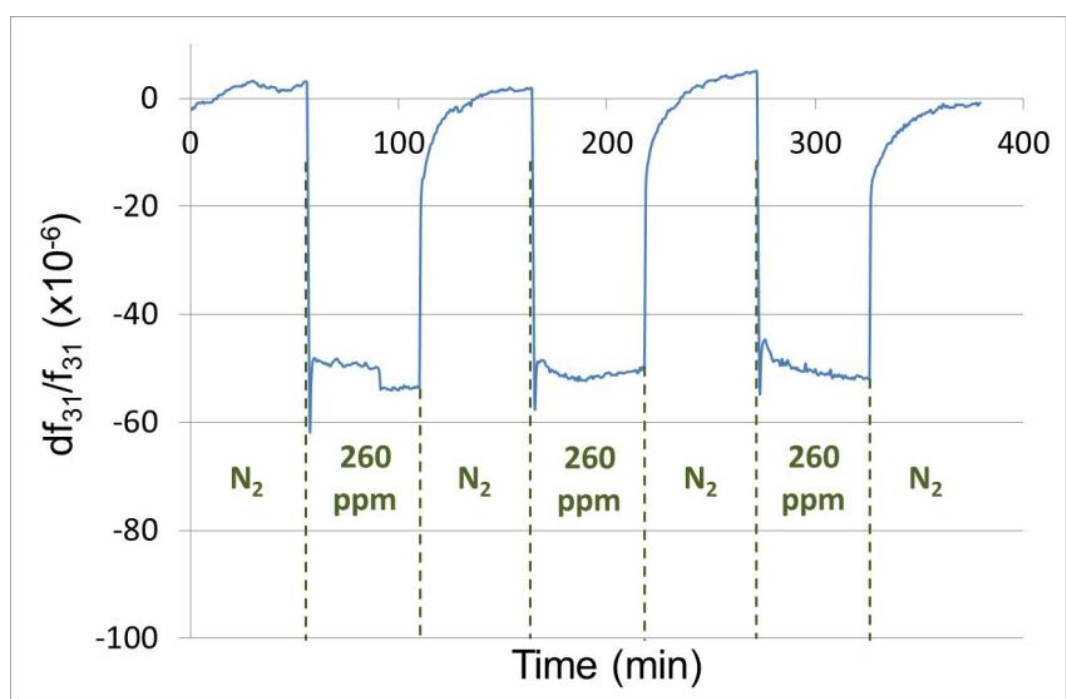

Fig.8. Repeatability of the cantilever's response to a toluene concentration of 260ppm (0.3V oscillating voltage)

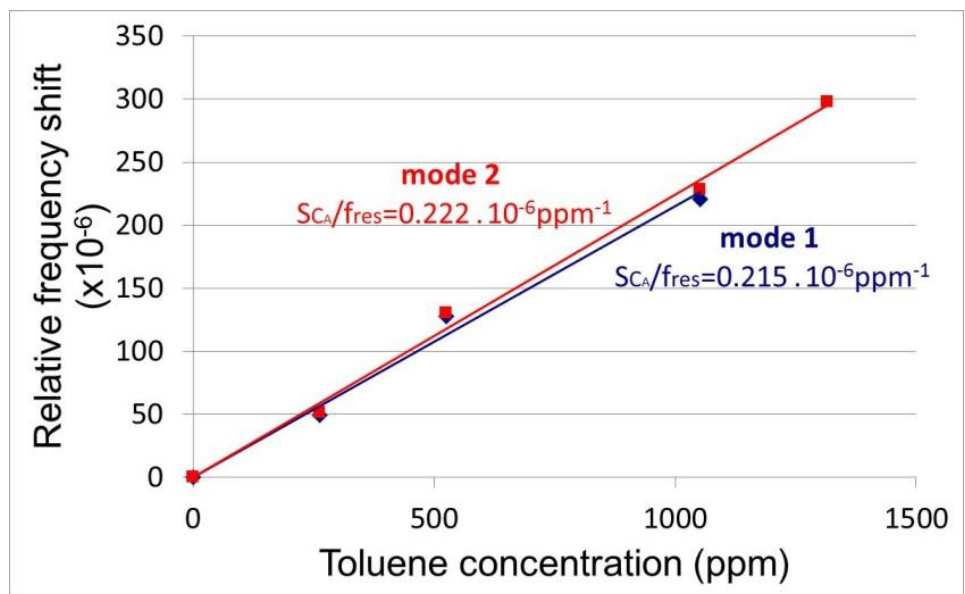

Fig.9. Relative resonant frequency shifts as a function of toluene concentrations measured for the first and second longitudinal 31 modes of the $8 \times 2 \times 0.095 \mathrm{~mm}^{3}$ PZT cantilever ( $0.3 \mathrm{~V}$ oscillating voltage)
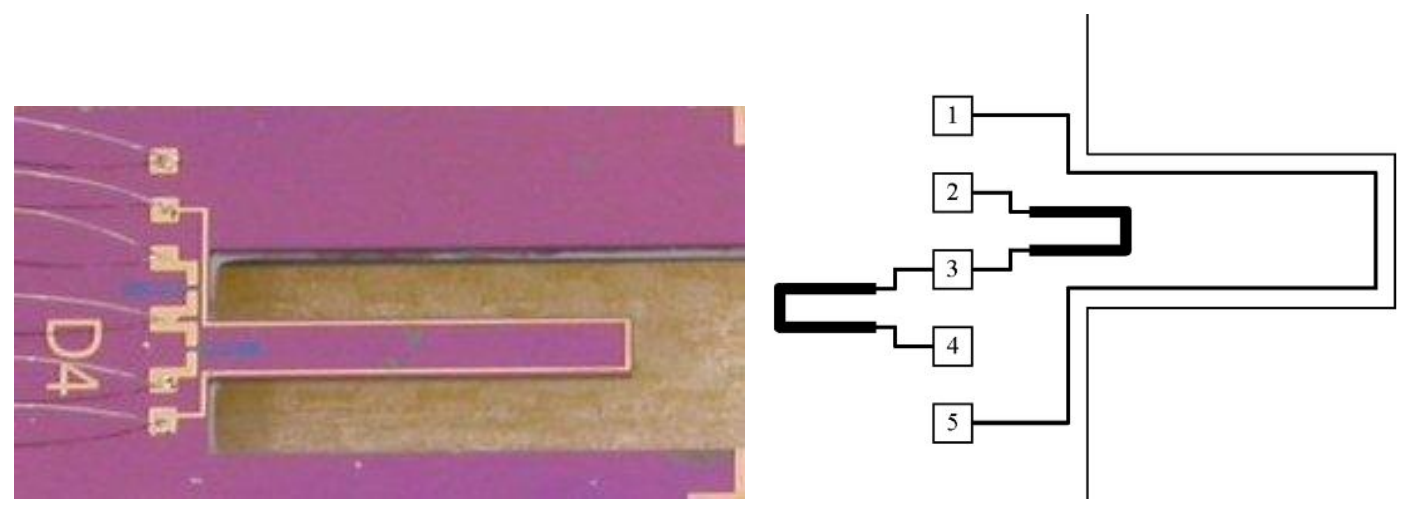

Fig. 10. Silicon cantilever $\left(5 \times 0.4 \times 0.059 \mathrm{~mm}^{3}\right)$ with electromagnetic actuation and piezoresistive measurement (a) photograph (b) electrical connection diagram 


\section{Biographies of Authors}

Hélène Debéda engineer in Physics of materials received the $\mathrm{PhD}$ degree from Bordeaux University, France, in 1996, for her work on the selectivity and reliability of thick film methane gas sensors. From 1996-1998 she obtained an European postdoc grant at the IMT Laboratory of Karlsruhe, Germany, to work on "Integrated piezoactuators made by the LIGA technique". Thanks to both the PhD and the post-doctoral position Hélène Debéda acquired a microsystem culture. She is now associate professor at the University of Bordeaux, IMS Laboratory where she is currently working on thick film technology applied to Microsystems and passive components.

Riadh Lakhmi graduated from Ecole Nationale Supérieure de Chimie et Physique de Bordeaux in 2008. He obtained, in the same year, his master in inorganic chemistry from the University of Bordeaux. He acquired PhD thesis at the University of Bordeaux in 2011. His research works concerns the realization of a physical force sensor and a chemical fluid sensor based respectively on a piezoresistive screen-printed layer upon a cantilever and a piezoelectric self-actuated and self-read out cantilever. Both cantilevers have been realized by combination of screen-printing technology and the use of a sacrificial layer. He's currently working, as a research engineer, on the application of printed piezoelectric devices.

Claude Lucat received his PhD in inorganic Chemistry from Bordeaux University in 1980 . He joined the Centre National de la Recherche Scientifique in 1979. Currently, he is Director of Research at IMS laboratory, University of Bordeaux, France. His main research interests were in thick-film materials for hybrid components and chemical sensors. Now, his research efforts are on the fabrication and characterization of free-standing structures for Microsystems applications, using the association of screen-printing technology and sacrificial layer method specifically developed at IMS. Microcantilevers or self-supporting devices for gas sensing, force sensors, energy harvesting, etc. are studied.

Isabelle Dufour graduated from Ecole Normale Supérieure de Cachan in 1990 and received the Ph.D. and H.D.R. degrees in engineering science from the University of Paris-Sud, Orsay, France, in 1993 and 2000, respectively. She was a CNRS research fellow from 1994 to 2007, first in Cachan working on the modelling of electrostatic actuators (micromotors, micropumps) and then after 2000 in Bordeaux working on microcantilever-based chemical sensors. She is currently Professor of electrical engineering at the University of Bordeaux and her research interests are in the areas of microcantilever-based sensors for chemical detection, rheological measurements and materials characterisation. 